\title{
Intrathecal Administration of AAV/GALC Vectors in 10-11 Day old Twitcher Mice Improves Survival and is Enhanced by Bone Marrow Transplant
}

\author{
Subha Karumuthil-Melethil ${ }^{1}$, Michael S. Marshall ${ }^{2}$, Clifford Heindel $^{1}$, Benas Jakubauskas ${ }^{2}$, \\ Ernesto Bongarzone ${ }^{2}$, and Steven J. Gray $1,3,{ }^{*}$ \\ ${ }^{1}$ Gene Therapy Center, University of North Carolina at Chapel Hill, Chapel Hill, North Carolina, \\ USA \\ ${ }^{2}$ Department of Anatomy and Cell Biology, University of Illinois at Chicago, Chicago, Illinois, USA \\ ${ }^{3}$ Department of Ophthalmology, University of North Carolina at Chapel Hill, Chapel Hill, North \\ Carolina, USA
}

\begin{abstract}
Globoid cell Leukodystrophy (GLD), or Krabbe disease, is an autosomal recessive neurodegenerative disease caused by the deficiency of the lysosomal enzyme Galactocerebrosidase (GALC). Hematopoietic stem cell transplantation (HSCT) provides modest benefit in presymptomatic patients but well short of a cure. Gene transfer experiments using viral vectors have shown some success in extending the survival of the mouse model of GLD, twitcher mice. In the present study, we compared three single stranded (ss) AAV serotypes, two natural and one engineered (with oligodendrocyte tropism), and a self-complementary (sc) AAV vector, all packaged with a codon-optimized murine $G A L C$ gene. The vectors were delivered via a lumbar intrathecal route for global CNS distribution onPND10-11, at a dose of $2 \times 10^{11} \mathrm{vg}$ per mouse. The results showed a similar significant extension of life span of the twitcher mice for all three serotypes (AAV9, AAVrh10, and AAV-Olig001) as well as the scAAV9 vector, when compared to control cohorts. The rAAV gene transfer facilitated GALC biodistribution and detectable enzymatic activity throughout the CNS as well as in sciatic nerve and liver. When combined with BMT from syngeneic wild type mice, there was significant improvement in survival for ssAAV9. Histopathological analysis of brain, spinal cord and sciatic nerve show significant improvement in preservation of myelin, with ssAAV9 providing the greatest benefit. In summary, we demonstrate that lumbar intrathecal delivery of rAAV/mGALCopt can significantly enhance the life span of
\end{abstract}

\footnotetext{
"Corresponding author: Steven J. Gray, graysj@email.unc.edu. AUTHOR DISCLOSURE STATEMENT

S.J.G. is an inventor for a patent application for the Olig001 capsid, and has received patent royalties from Asklepios Biopharma in relation to this intellectual property.

ROLE OF AUTHORS

S.K.M. did all of the experimental work except where otherwise stated. S.K.M. and S.J.G. designed the studies, coordinated studies with collaborators and core facilities, and wrote the manuscript. S.J.G. oversaw all activities related to the project and acquired the primary funding for the work. C.H. assisted with the survival characterization of the study mice, and the collection of mouse specimens for downstream analysis. E.R.B. supervised and funded the GALC activity and psychosine analyses, and provided input on that aspect of the study design. M.S.M. conducted initial sample processing and coordinated the psychosine analysis by the Research Resource Center at UIC. B.J. conducted the GALC activity assay on the samples sent to UIC.
} 
twitcher mice treated at PND10-11 and BMT synergizes with this treatment to further improve the survival.

\section{Graphical Abstract}
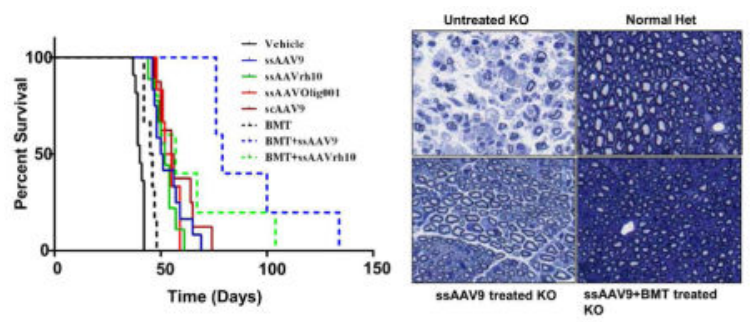

Intrathecal AAV-mediated gene therapy synergized with Bone Marrow Transplant (BMT) in 10-11 day old twitcher mouse model of Krabbe disease to extend the survival as well as to improve the pathology in the central nervous system and sciatic nerve.

\section{Keywords}

AAV; Krabbe; globoid cell leukodystrophy; GALC; gene therapy; intrathecal

\section{INTRODUCTION}

Krabbe disease or Globoid cell Leukodystrophy is a severe neurodegenerative disease resulting from the deficiency of lysosomal enzyme Galactocerebrosidase (GALC) (Suzuki and Suzuki, 1970). It is inherited in an autosomal recessive manner and characterized by rapid and progressive demyelination along with the presence of large multinucleated globoid cells. Deficiency of GALC leads to defective catabolism and subsequent accumulation of psychosine, a toxic metabolite causing apoptosis of myelin forming cells (Nagara et al., 1986; Tanaka et al., 1993; Taniike et al., 1999). Additionally, inefficient degradation of another substrate of GALC, galactosylceramide, is believed to attract macrophages capable of phagocytizing it and transforming into the large globoid cells. In its acute infantile form, the clinical symptoms start around 6 months of age, progressing very rapidly to death around 2 years of age (Wenger et al., 1997). Later-onset Krabbe disease exhibits highly variable clinical phenotypes depending on the levels of residual GALC activity. The only available standard-of-care treatment for this disease is Hematopoietic Stem Cell Transplantation (HSCT) which has been shown to slow down the disease progression in pre-symptomatic infants and some later-onset patients (Krivit et al., 1998; Escolar et al., 2005; Duffner et al., 2009).

Several naturally occurring animal models of Krabbe disease have been identified. This includes the most commonly used twitcher mouse (Duchen et al., 1980; Kobayashi et al., 1980), the terrier dogs (Fankhauser et al., 1963; Fletcher et al., 1966; Suzuki et al., 1970) and the rhesus monkey (Baskin et al., 1989). These animal models, especially the twitcher mice, have helped researchers to better understand the pathology of the disease as well as to test different therapeutic interventions. 
Gene transfer utilizing viral vectors to deliver the correct copy of the defective gene is becoming an attractive approach for treating several lysosomal storage diseases including Krabbe disease. Recent studies utilizing recombinant Adeno Associated Virus (AAV) have shown some success in treating the twitcher mice. Wild type AAV has a $4.7 \mathrm{~kb}$ singlestranded (ss) DNA genome and belongs to the parvovirus family (McCarty et al., 2004; Gonclaves, 2005). Although AAV infects humans, it is non-pathogenic and it is classified as a dependovirus because it is unable to execute a lytic infection without co-infection with a helper virus such as adenovirus or herpesvirus (McCarty et al., 2004; Gonclaves, 2005). Important for CNS gene therapy applications, AAV can transduce non-dividing cells and has the ability to confer long-term stable gene expression without associated inflammation or toxicity (Haberman et al., 2003; Bessis et al., 2004; Gonclaves, 2005). Recombinant AAV vectors contain no AAV coding sequences, and they package any DNA cassette within its size constraints as long as the DNA is flanked by $\sim 145$ bp inverted terminal repeats (ITRs). An alternative form of the AAV genome is the self-complementary (sc) genome design, which utilizes a mutated version of one of the ITRs. Sc AAV vectors have 10- to 100-fold higher transduction efficiency than traditional ss AAV vectors (McCarty et al., 2001; McCarty et al., 2003; Gray et al., 2011b), facilitating applications designed for global delivery of the virus particles, such as via intravenous (IV) or intra-cerebrospinal fluid (CSF) injection. However, a potential drawback of sc AAV vectors for some genes is that the packaging capacity is cut in half, to approximately $2.3 \mathrm{~kb}$ of foreign DNA. The characteristics of AAV make it an attractive vector in therapeutic strategies for Krabbe disease.

The ability of AAV serotype 9 (AAV9) to transduce neurons and glia in the CNS after an IV injection has raised new possibilities for global CNS delivery of therapeutic transgenes in rodents, cats, and non-human primates (Duque et al., 2009; Foust et al., 2009; Gray et al., 2011b). However, the lack of target specificity, high doses of vector required, high prevalence of anti-AAV9 neutralizing antibodies in the human population, and high loads of vector that are delivered to peripheral organs create challenges for translating this approach to humans. More recently, several laboratories have demonstrated the possibility of achieving widespread gene transfer throughout the CNS following injection of AAV into the cerebrospinal fluid (CSF). In pigs this resulted in 50-100\% transduction of spinal cord motor neurons along with transduction of neurons and glia in the brain at a dose of $1.7 \times 10^{11}$ vector genome ( $\mathrm{vg}) / \mathrm{kg}$ (Federici et al., 2012). In cats, dogs, and non-human primates, widespread CNS gene transfer could be achieved after a single intra-CSF injection of AAV9 vectors (Samaranch et al., 2012; Samaranch et al., 2013; Haurigot et al., 2013; Bucher et al., 2013; Gray et al., 2013; Passini et al., 2014). AAVrh10 is an alternative capsid that has been described as being capable of crossing the blood-brain barrier, and may be amenable to widespread transduction after intrathecal administration (Hu et al., 2010; Zhang et al., 2011; Yang et al., 2014).

AAV gene therapy for treating GLD has utilized different serotypes, different routes of administration and different ages for the initiation of therapy. Direct administration of AAV1 packaged with mouse GALC gene into the brains of neonatal twitcher mice extended their lifespan from 42 days to up to 66 days along with sustained GALC activity, improved myelination and attenuated symptoms (Rafi et al., 2005). An AAV5 vector expressing 
GALC was reported to increase the life expectancy of twitcher from 38 days to 52 days when injected intracranially on day 3 of age (Lin et al., 2005). They also reported an increase in GALC activity and improvement in their performance in behavioral tests. Rafi and coworkers (2012) showed that a combination of intracerebroventricular, intracerebellar and intravenous injections of AAVrh10 vectors with mGALC in neonatal mice increased the average life span of twitcher to 104 days. In the same study, addition of another IV injection at PND7 further improved the survival to an average of 120 days. They observed only a modest increase in lifespan with only the IV approach at this age; but in a follow up study, they (Rafi et al., 2014) reported that twitcher mice receiving a single IV injection of AAVrh10 on PND10 had an average life span of about 20-25 days longer than the untreated twitcher mice.

The synergistic effect of Bone Marrow transplant on AAV gene therapy was first reported by Lin and coworkers in 2007. In that study animals that received intracranial injections of AAV5/mGALC and myeloreductive BMT at the neonatal stage had an average life span of $104+/-7$ days when compared to an AAV only treatment with 49+/-1 days and BMT only treatment with $44+/-1$ days. In another report from the same group, CNS-directed gene therapy consisting of intrathecal and intracranial AAV5-GALC injections in neonatal twitcher, combined with BMT increased the median life span of twitcher to 123 days (Reddy et al., 2011). In a more recent report Rafi et al. (2015) showed that a combination of BMT and a single IV injection of AAVrh10-GALC delivered at PND9-10, greatly extended the lifespan and normal behavior of twitcher with improved CNS and PNS pathology. These studies provided compelling evidence that a combination approach is capable of treating different aspects of GLD and produce a significantly better therapeutic outcome than any single treatment.

The present study utilized intra-CSF AAV delivery via the lumbar puncture route in 10-11 day old twitcher mice. We compared three different AAV serotypes, packaging a codonoptimized mouse GALC construct along with a self-complementary design packaged into AAV9 capsid. We designed two constructs for packaging GALC into ssAAV and scAAV vectors for delivery into twitcher mice. The expression cassette for ssAAV vectors had a Chicken-Beta Actin (CBA-CAGGS) promoter and SV40 poly-adenylation site (polyA) driving the expression of a codon optimized murine GALC. This construct was packaged into three AAV serotypes, AAV9, AAVrh10 and AAVolig001. A minimal JeT promoter and a short synthetic poly A along with a truncated mouse GALCopt was used in the design for scAAV. The purpose of this experiment was to test if the best scAAV/GALC design could afford a better rescue than the widely used ssAAV/GALC construct. Our hypothesis was that even though the net expression of GALC afforded by this design would be weaker, the increased distribution to more cells might provide a greater overall rescue.

There was significant extension of life span with all the AAV vectors tested and they all produced similar survival benefit. We also tested the combination of two serotypes individually with BMT after chemical conditioning using Busulfan. As reported earlier by other researchers, we observed a synergistic effect of BMT on AAV gene transfer in terms of survival and pathological improvement. The therapeutic efficacy of all the treatments were evaluated on the basis of survival, CNS and peripheral nerve histopathology. 


\section{MATERIALS AND METHODS}

\section{Plasmid Design and Vector Preparation}

For the purpose of this study, we designed two constructs to be packaged into single stranded (ss) and self-complementary (sc) AAV vectors (Figure 1A). A codon-optimized and myc tagged mouse GALC (mGALCopt-myc) was cloned under a Chicken-Beta Actin (CBA-CAGGS) promoter along with a SV40 poly-Adenylation (poly A) tail for packaging into a traditional ssAAV. The codon-optimized mouse GALC was a kind gift from Dr.Tal Kafri at University of North Carolina at Chapel Hill. This expression cassette was packaged into three AAV serotypes, AAV9, AAVrh10 and AAVOlig001. The Olig001 capsid was developed by Dr. Steven Gray and Dr. Thomas McCown at University of North Carolina at Chapel Hill and found to transduce mostly oligodendrocytes after intracranial administration into mice and rats (data not shown). A minimal JeT promoter (Tornoe et al., 2002) combined with a short synthetic poly A was used to drive the expression of a truncated mGALCoptmyc (sequence starts with the $2^{\text {nd }}$ start codon) in the construct design for scAAV.

Recombinant AAV vectors were generated using proprietary methods developed at the UNC Gene Therapy Center Vector Core facility (Chapel Hill, NC, USA) (Gray et al., 2011a; Grieger et al., 2016). The AAV vectors produced for this study included: ssAAV9/ mGALCopt, ssAAVrh10/mGALCopt, ssOlig001/mGALCopt and scAAV9/mGALCopt. Vectors were dialyzed in phosphate-buffered saline (PBS) containing 5\% D-sorbitol and 350mM NaCl. Viral titers were determined by qPCR as described (Gray et al., 2011a).

\section{Mouse Studies}

All the experiments involving the use of animals described in this report were approved by the University of North Carolina-Chapel Hill Institutional Animal Care and Use Committee. The naturally occurring mouse model for Krabbe disease, the twitcher mouse (Strain B6.CEGalc $^{t w i} / \mathrm{J}$ ) was originally sourced from Jackson Laboratory (Bar Harbor, ME) but provided by Dr. Mark Sands (Washington University, St. Louis), and the colony was maintained at the University of North Carolina at Chapel Hill.

The timeline of therapeutic interventions in twitcher mice for the purpose of this study is depicted in figure 1B. The intrathecal delivery of vehicle control and AAV vectors $\left(2 \times 10^{11}\right.$ $\mathrm{vg} /$ mouse) were done on PND10-11 into twitcher mice. Concentrated AAV stocks were used to keep the injection volume typically between 5-10uL although some initial studies used injection volumes as high as $18 \mathrm{uL}$. For the mice that received Bone Marrow Transplant on PND9-10, they were chemically conditioned by intraperitoneal injection of Busulfan (35mg/kg body weight) onPND8-9. These mice were given neomycin containing water $(0.5 \mathrm{~g} / \mathrm{L})$ for 50 days following the treatment. The bone marrow cells were collected from the femur and tibia of 8-10wk old syngeneic WT C57B1-6 or B6 mice heterozygous for eGFP (Okabe et al., 1997). The eGFP-positive mice were kindly provided by Dr. Mark Sands. The bone marrow cells were injected intraperitoneally into twitcher on PND9-10 at the rate of 40 million live cells per mouse. One set of the control and treated mice were monitored for survival and euthanized at humane end point. Tissue samples were collected for analyzing GALC activity, psychosine levels and vector biodistribution. A separate set of control and 
treated mice were euthanized on PND35 for performing histo-pathological examination. At sacrifice, these mice were transcardially perfused first with PBS containing $1 \mathrm{U} / \mathrm{mL}$ heparin followed by $4 \%$ Paraformaldehyde (PFA) in PBS. The brain and spinal cord tissues were preserved in Neutral Buffered Formalin (NBF). They were processed, embedded in paraffin and used for histological analysis. The sciatic nerves from these mice were post-fixed in 0.15M Karlsson and Schultz phosphate buffer containing 2.5\% glutaraldehyde and 2\% PFA. They were processed and resin-embedded to be used for downstream analysis.

\section{GALC Enzymatic Activity Assay}

Samples were lysed in double-distilled and deionized water $\left({ }_{d d} \mathrm{H}_{2} \mathrm{O}\right)$, and tissue homogenates $(20 \mu \mathrm{g})$ were incubated with synthetic fluorescent GALC substrate (6Hexadecanoylamino-4-methylumbelliferyl-beta-D-galactoside; Moscerdam Substrates) for $17 \mathrm{hr}$ at $37^{\circ} \mathrm{C}$. After incubation, the reaction was stopped, and fluorescence was measured using a Beckmann Coulter DTX 880 multimode detector using excitation/emission wavelengths of $385 \mathrm{~nm}$ and $450 \mathrm{~nm}$, respectively.

\section{Quantitative PCR Analysis of Vector Genomes}

Analysis of vector biodistribution was done by quantitative PCR (qPCR). Tissue DNA was purified and quantified as described (Gray et al., 2011a). The quantification was specific for the codon-optimized mouse $G A L C$. The primer sequences are as follows: mGALCopt-F-5' CACCATCAACAGCAACGTGG-3' mGALCopt-R-5' GTTCCTCGTAGTAGCTGGCC- $3^{\prime}$. Data is reported as the number of double-stranded $G A L C$ molecules per 2 double-stranded copies of the murine LaminB2 locus, or in other words, the number of vector DNA copies per diploid mouse genome.

\section{Immunohistochemistry}

The Hematoxylin-Eosin (H\&E) staining for brain and spinal cord sections were done using an autostainer XL from Leica Biosystems by the Translational Pathology Laboratory and the Animal Histopathology Core at UNC, respectively.

The processing and staining of sciatic nerve samples were done by the Microscopy Services Laboratory in the Department of Pathology and Laboratory Medicine, UNC as per their standardized protocol. Nerve samples ( $3 \mathrm{~mm}$ segments) were post-fixed in $1 \%$ Osmium tetroxide/ $0.15 \mathrm{M}$ sodium phosphate buffer for 90 minutes at $4{ }^{\circ} \mathrm{C}$, rinsed in deionized water, dehydrated through increasing concentrations of ethanol and finally with propylene oxide. Tissue samples were infiltrated with a 1:1 mixture of propylene oxide: Polybed 812 epoxy resin (1A:2B formulation, Polysciences, Inc., Warrington, PA) for 3 hours followed by an overnight infiltration in $100 \%$ resin. The nerve segments were embedded in fresh epoxy resin and polymerized for 24 hours at $60^{\circ} \mathrm{C}$. Using a diamond knife, 1 micrometer crosssections of the nerve were cut, mounted on glass slides and stained with $1 \%$ toluidine blue $\mathrm{O}$ in $1 \%$ sodium borate. Slides were mounted with a \#1.5 coverslip and DPX mountant (Sigma-Aldrich, St. Louis, MO).

Luxol Fast Blue (LFB) staining for brain and spinal cord was done by the Animal Histopathology Core at UNC. Briefly, the brain and spinal cord sections were immersed in 
$0.05 \% \mathrm{LiCO} 3$ for the color development and then decolorized with $70 \%$ ethyl alcohol. The sections were oxidized using $1 \%$ Periodic acid for 5 minutes, followed by rinsing with water and dehydration with ethyl alcohol and xylene.

All the slides were digitally imaged in the Aperio ScanScope XT (Leica) using 20x objective. The image analysis was done using Aperio ImageScope (Leica).

\section{Stastistical Analysis}

GraphPad Prism software (GraphPad Software, Inc., La Jolla, CA) was used for the analysis of extension of lifespan as a result of different treatments. Using Kaplan-Meier curve analysis and Mantel-Cox log rank test, each treatment was compared individually to the vehicle injected to determine the significance of the survival benefit. Additionally, comparisons were made between AAV only and combination with BMT cohorts. For analysis of vector biodistribution and GALC activity data, Standard Error of Mean (SEM) were calculated and a two tailed Student's t test was used when required for comparison between treatments.

\section{RESULTS}

\section{General Approach}

We designed two constructs for packaging GALC into ssAAV and scAAV vectors for delivery into twitcher mice (Figure 1A). The expression cassette for ssAAV vectors featured a Chicken-Beta Actin (CBA-CAGGS) promoter along with a SV40 poly-adenylation site (polyA) driving the expression of a codon optimized murine GALC. Three AAV serotypes, AAV9, AAVrh10, and AAVOlig001, were used to deliver this cassette. A truncated mGALCopt-myc (sequence starts with the $2^{\text {nd }}$ start codon) cloned under a minimal JeT promoter combined with a short synthetic poly A was included in the construct design for scAAV. The relative expression afforded by the ss (CBA) and sc (JeT) constructs was evaluated in vitro. Additionally, we used another construct coding for WT mouse GALC used by few other researchers, but with slightly different transcription elements. When AAV9 vectors were used to deliver the CBA (ss) or JeT (sc) construct, the CBA promoter produced $\sim 40$ fold more GALC mRNA (Supplemental Methods and Supplemental Table 2). We did not see any significant difference between the WT and codon-optimized murine GALC at the mRNA level in this experiment.

For the studies detailed in here, we treated the twitcher mice between the ages of 8-11 days. For vehicle or AAV-only treatments, the intrathecal delivery was done in 10-11 day old twitcher via lumbar puncture. Mice receiving BMT were injected intraperitoneally with busulfan (35mg/kg body weight) 24 hours before the transplant. Bone marrow cells were collected from the femur and tibia of WT eGFP+ mice and 40 million live cells were injected IP into 9-10 day old twitcher. All the treated mice were monitored for weight gain/ loss on alternate days and survival was recorded as described.

To visualize and quantify the level of engraftment, we euthanized four twitcher mice transplanted with $\mathrm{GFP}^{+}$bone marrow along with two untreated mice (Supplemental methods, Supplemental figure 1 and Supplemental Table 1). We included a $\mathrm{GFP}^{+}$mouse as a 
positive control for the assays (data not shown). We observed an engraftment level of up to $64 \%$ in the blood and up to $3 \%$ in the brain. By IHC, the engraftment looked better in the brain compared to that in spinal cord and the distribution of donor cells was not homogenous in the brain with more cell in the upper cerebral cortex and cerebellum.

\section{Vector Distribution and Gene Expression}

As an initial comparison of the treatment cohorts, we assessed the overall distribution of the vector DNA as well as the distribution of the expressed GALC enzyme.

The biodistribution of each vector in major organs and target tissues was analyzed at the humane end point using real time quantitative PCR (qPCR) and expressed as copies of the delivered mGALCopt genome per 2 copies of diploid mouse genome (Figure 2A). The tissue from vehicle-injected negative control and BMT-treated twitcher mice did not have any detectable viral genomes, which was expected since the codon-optimized transgene had a sequence distinct from the endogenous mouse GALC gene. The average vector distribution observed for ssAAV9 $(n=9)$ and ssAAVrh10 $(n=9)$ after intrathecal delivery was very similar in the peripheral organs, spinal cord and sciatic nerve, but we observed a higher distribution trend in the front (rostral) brain ( $\mathrm{p}=0.11$ ) for ssAAV9. The ssAAVOlig001 vector had highly reduced distribution to peripheral organs, but was comparable to AAV9 and AAVrh10 in hind brain and spinal cord. The self-complementary vector had a slightly higher mean copy number in the spinal cord, but did not surpass the ssAAV9 vector in the brain or sciatic nerve. Combining BMT with vector delivery appeared to marginally improve the vector biodistribution for both AAV9 and AAVrh10 in the periphery as well as CNS, but this effect was not significant.

The enzymatic activity of GALC was determined in twitcher tissues collected at humane endpoint along with that of a heterozygous (het) littermate collected at PND40 (Figure 2B). There was no detectable activity in tissues of vehicle-treated mice. In the liver, ssAAV9- and ssAAVrh10-treated mice recorded GALC activity higher than the normal het mouse. There was a significant increase in liver GALC activity when combined with BMT for ssAAV9 $(\mathrm{p}=0.007)$, and a trend towards increase for ssAAVrh10 $(\mathrm{p}=0.15)$. In the brain, for all AAVtreated animals, low levels of activity were observed. The BMT and ssAAV9 combination showed higher GALC activity in the front brain compared to all other treatments. Mouse to mouse variability was very high for the GALC enzymatic activity analysis for spinal cord and nerve samples; an overall increase in GALC activity was observed for all treatment cohorts compared to vehicle, but it was unclear whether any treatment was more effective in these tissues. A general trend showed higher GALC activities when AAV is combined with BMT. Interestingly, although GALC activities were above normal physiological levels in the tissues examined for each treatment, there was still accumulated psychosine (Supplemental Figure 2).

Overall, the biodistribution analysis indicates that all the AAV vectors were able to distribute the GALC transgene throughout the CNS, but the Olig001 capsid had highly reduced distribution to the sciatic nerve and peripheral organs. Although superphysiological levels of GALC were achieved in some tissues this did not translate to a clear reduction in psychosine. 


\section{Survival}

The twitcher mice, both control and treated, were monitored for survival. A 20\% weight loss from the recorded peak weight is considered to be the humane end point for assessing the life span of the mice, and was scored as a death. A Kaplan-Meier curve analysis was performed for the survival proportions plotted in Figure 3. The median life span for the control mice was 40 days in our colony. Mice treated with BMT had a median survival of 45.5 days, whereas the AAV only treatments had median survivals ranging from 50.5 to 55.5. The combined AAV+BMT treatments had further extensions in median lifespan to 79 and 57, for AAV9 and AAVrh10 respectively. These extensions of life span compared to vehicle treated mice were all significant $(\mathrm{p}<0.0001$ for ssAAV9, ssAAVrh10 and scAAV9; $\mathrm{p}=0.0003$ for ssOlig001; $\mathrm{p}=0.0021$ for BMT only; $\mathrm{p}=0.0008$ for BMT+ssAAV9 and $\mathrm{p}=0.0008$ for BMT+ssAAVrh10) when analyzed with Log rank (Mantel-Cox) test. The combination treatment of BMT with ssAAV9/mGALCopt significantly $(\mathrm{p}=0.0004)$ enhanced survival when compared to ssAAV9 only. However, the addition of BMT to the ssAAVrh10 treatment did not lead to a significant extension in median survival compared to ssAAVrh10 alone. Two mice in the BMT+ssAAVrh10 treatment cohort had survivals approaching that seen with the ssAAV9+BMT combination, but overall there was a high degree of variability in the survival of this cohort. As such, there was not a significant difference between the AAV9+BMT combination and the AAVrh10+BMT combination. Based on the data from these cohorts, in terms of survival, the BMT treatment provided the least benefit and all AAV treatments provided a greater but approximately equivalent benefit. It isn't clear if the addition of BMT to the AAVrh10 treatment conferred a greater benefit, but the addition of BMT to the AAV9 treatment provided the best survival outcomes of all the treatments tested.

\section{Histopathology}

In order to stratify the treatment effects further, a histological assessment was conducted on key areas that are believed to contribute to the disease progression of GLD. This included the sciatic nerve, lumbar spinal cord, cervical spinal cord, and cerebellum. Demyelination and degeneration in these areas is well-described as part of the overall disease progression (Fletcher et al., 1977; Hoogerbrugge et al., 1988; Levine et al., 1994; Fletcher et al., 2010; Rafi et al., 2014; Rafi et al., 2015).

To evaluate the effect of treatments on peripheral nerves of twitcher mice, we performed histopathological analysis on the sciatic nerves of normal het littermates and affected control and treated mice at PND35. At this defined end point, upon gross examination it was noted that the control vehicle-treated twitcher mice were much weaker in appearance and had swollen sciatic nerves compared to all those which received treatment. To assess the ultrastructure of the sciatic nerves, they were embedded in resin and semi thin (1 um) sections were stained with toluidine blue to detect the presence of myelin. Two nerves from 3 mice each were analyzed per treatment except for BMT+ssAAVrh10 where only 2 mice were analyzed and representative images are shown (Figure 4). The sciatic nerve from the vehicle-treated twitcher showed significant loss of myelin and axons with overall marked degeneration clearly visible. The normal heterozygous mouse had intact myelin and normal distribution of axons. The BMT+ssAAV9 treated twitcher appeared to have a near normal sciatic nerve histology with no detectable myelin loss and near normal axonal count. Similar 
observations could be made for ssAAV9 only treated animals where very little demyelination and axonal loss is noted. The ssAAVOlig001, scAAV9 and BMT-only treated animals showed only a modest improvement in sciatic nerve pathology over the control twitcher mice. The mice receiving ssAAVrh10 alone and in combination with BMT had an intermediate level of pathology compared to the vehicle treated twitcher mice and het controls.

To quantify the differences observed in axonal loss and demyelination between different treatment cohorts, we used the HALO platform for axon quantification from Indica Labs to calculate G-ratios (axon diameter/outer myelin diameter) across the entire sciatic nerve cross sections (Supplemental Figure 3). This quantitative analysis showed normalization of Gratios for the treated animals, to an extent that is generally consistent with the qualitative representative images depicted in Figure 4.

To assess the treatment effects proximal and distal from the injection site, demyelination in the lumbar spinal cord, cervical spinal cord, and cerebellum was assessed by luxol fast blue staining (Figures 5, 6, and 7 and Supplemental Figures 7-13). The images are representative of three mice per treatment except for the BMT+ssAAVrh10 treatment $(n=2)$. Similar sections were stained with hematoxylin and eosin (Supplemental figures 4, 5 and 6) and images were analyzed in parallel to understand the pathology. The cerebellum images in Figure 5 are focused on the white matter tracts where there is distinct focal destruction of myelinated fibers in the untreated twitcher mice. Intact myelin was observed in normal het mice. In the area most distal from the injection site, the cerebellum, myelin was best preserved by the ssAAV9 treatment (with or without BMT). Improvement was noted with all other treatments as well. In the areas more proximal to the injection site, the lumbar and cervical spinal cord, myelin was relatively well-preserved with the ssAAV9 and ssAAVrh10 treatments, and further improved with the addition of BMT. Minor benefit was seen with the ssAAVOlig001, scAAV9, and BMT only treatments, and in general the treatment effects were more pronounced in the lumbar spinal cord than the cervical spinal cord. As might be expected, for all treatments except BMT, the greatest rescue occurred closest to the lumbar injection site and the smallest effects were noted distally, in the cerebellum. BMT had a relatively better therapeutic effect in the cerebellum than either of the spinal cord regions. This correlates with the level of engraftment observed in brain and spinal cord areas (Supplemental Figure 1). None of the treatments could completely rescue this pathology, but the ssAAV9+BMT combination had the best preservation of myelin in the spinal cord and brain of twitcher mice, with close to complete normalization of the white matter near the injection site (lumbar spinal cord).

\section{DISCUSSION}

Apart from the conclusions regarding the treatment of Krabbe disease, we report the first biodistribution analysis that we are aware of directly comparing AAV9 and AAVrh10 after intrathecal administration. AAVrh10 has been characterized in the context of direct intracranial injection and intravenous administration, but our data indicates that it may be a viable vector to support gene transfer by intrathecal administration. That said, our results 
indicate greater therapeutic benefit was conferred by AAV9 compared to AAVrh10, at least in the context of Krabbe disease.

There were clear stratifications among the pathological outcomes of individual treatments that didn't necessarily translate to better survival. According to survival outcomes, BMT alone provided the least benefit. All the capsid and vector designs provided an equivalent survival benefit. Combination with BMT significantly increased survival with AAV9, but this synergy was only marginal and not significant with AAVrh10. When examining the pathology, all treatments provided some improvement to the spinal cord, cerebellum, and sciatic nerve. However, the treatment with AAV9 was particularly striking in the degree of tissue morphology preservation, and this "normalization" was increased further with the addition of BMT. The reason for this improved outcome with AAV9 is only partially clear. The vector DNA biodistribution is similar between the 3 capsids, with the exception of markedly reduced biodistribution of AAV-Olig001 to the forebrain, sciatic nerve, and peripheral organs. It makes some sense therefore that, of the 3 capsids evaluated, AAVOlig001 provided the least GALC expression and reduction in pathology to the sciatic nerve. Also, previous studies had described the marked reduction in oligodendrocyte numbers in twitcher as early as two weeks of age (Taniike et al., 1999) and this could have led to a decreased target cell population for this vector when used in 10-11 day old twitcher. Further, the scAAV9 construct expressed significantly less GALC than ssAAV9, suggesting that although scAAV would be expected to express GALC in more cells, the weaker JeT promoter was not able to match the net expression afforded by the CAGGS promoter. We want to point out that the expression afforded by this scAAV construct was able to provide a statistically equivalent survival benefit as the ssAAV design, but had very modest benefit in improving the overall pathology. Perhaps most interesting is the observation that all 3 capsids provided normalized or superphysiological levels of GALC across the brain, spinal cord, and sciatic nerve, but there was still accumulated psychosine that was indistinguishable from untreated twitcher mice. Possible explanations for this include uneven distribution of GALC-expressing cells or populations of cells that are refractory to uptake of GALC via the mannose-6-phosphate pathway. Another possibility is that psychosine accumulation was slowed, but since tissue was collected at the humane endpoint all the animals showed equal psychosine levels. Overall, we have 2 major conclusions from this study: 1) Using the intrathecal route of administration, AAV9 is the best of the 3 capsids tested. 2) BMT clearly synergized with the intrathecal AAV9 treatment, providing a substantial benefit over AAV9 alone.

Comparing our findings with those recently published by the Wenger lab, several similarities and differences can be drawn. The mice were treated with identical vector doses $\left(2 \times 10^{11} \mathrm{vg} /\right.$ mouse) at identical treatment ages, but the route of AAV delivery was different and only AAVrh10 was investigated IV (Rafi et al., 2014; Rafi et al., 2015). The mice receiving intrathecal AAV vector only had a median lifespan of 50.5 to 55.5 in our study, and AAVrh10 provides a median lifespan of approximately 65 days after IV injection (Rafi et al., 2015). Although we attempted to follow the same BMT regimen as reported by Rafi et al., our transplanted mice had a median life span of 45.5 days, short of 77 day median survival observed by Rafi et al. The difference in the efficacy of BMT may explain why a more pronounced extension in survival was seen when intravenous AAVrh10 therapy was 
combined with BMT, resulting in survival of multiple mice past 300 days. In contrast, we were unable to see this high level of synergy they observed with the combination of BMT and intrathecal delivery of AAVrh10-GALC and the combination of intrathecal AAV9 with BMT in our study resulting in a more modest survival extension to 79 days. Based on the survival data with AAV vectors alone, the data suggests that the IV and intrathecal approaches are equivalent in terms of survival outcomes, but a direct comparison can't be drawn regarding the synergy with BMT. Taken together, our studies identified that both AAV9 and AAVrh10 could provide a benefit, but only AAVrh10 was tested in Rafi et al. We would not infer from our results whether AAV9 might be better by an intravenous route of administration, and this remains to be tested.

Our study follows a series of published studies that document the synergy between BMT and AAV-mediated gene therapy in the twitcher mice (Lin et al., 2007; Reddy et al., 2011; Rafi et al., 2015). Our work further strengthens this general finding supporting the need for a combinatorial treatment, which is now seen with 3 different AAV-mediated approaches (neonatal intracranial injection with AAV5, intravenous injection with AAVrh10, and intrathecal injection with AAV9) in 3 separate and independent laboratories.

There is a reasonable expectation that the approach and results from these studies are translatable to humans. The intrathecal route of administration for AAV9 has been confirmed by multiple laboratories to confer widespread gene transfer across the CNS, across multiple small and large animal models including non-human primates (Samaranch et al., 2012; Haurigot et al., 2013; Gray et al., 2013; Bucher et al., 2013; Passini et al., 2014). There is also precedence for AAV9-mediated intrathecal gene transfer in a human clinical trial, which was pioneered by our group for Giant Axonal Neuropathy (clinicaltrials.gov identifier NCT02362438). An IV approach with an AAVrh10 vector in combination with BMT is also justified as an alternative approach based on the data by Rafi et al., 2015. Although there is no precedent for injecting AAVrh10 vectors IV in humans, there is precedence for injecting similar doses of AAV9 vectors IV into infants with Spinal Muscular Atrophy (clinicaltrials.gov identifier NCT02122952). Either approach is likely to provide substantial benefit to patients beyond that which is provided by HSCT alone, both approaches are feasible for human translation, and both are supported by studies at a relevant postnatal age.

\section{Supplementary Material}

Refer to Web version on PubMed Central for supplementary material.

\section{Acknowledgments}

Funding for this research was provided by the Hunter's Hope Foundation (S.J.G.), the Legacy of Angels Foundation (S.J.G., E.R.B.), NIH F30NS090684 (M.S.M.), NIH R01NS065808 (E.R.B.), and R21NS087474 (E.R.B.). Indirect administrative support for S.J.G. was provided by Research to Prevent Blindness to the UNC Department of Ophthalmology. We thank Violeta Zaric at UNC for her technical assistance in the biodistribution studies, and Dr. Diane Armao at UNC for expert histological consultations. We acknowledge Zane Hauck and Richard B. van Breemen at the University of Illinois at Chicago for technical support for the psychosine analysis. We acknowledge the UNC Vector Core and Jude Samulski at UNC for AAV vector production. We thank Yongjuan Xia and the staff at the UNC Translational Pathology Laboratory (TPL) for expert technical assistance. The UNC Translational Pathology Laboratory is supported in part, by grants from the National Cancer Institute (2-P30-CA016086-40) and the UNC University Cancer Research Fund (UCRF). We acknowledge the LCCC Animal Histopathology Core Lab at UNC for their expert technical assistance. We thank Kristen White and Vicky Madden at the Microscopy 
Services Laboratory in the Department of Pathology and Laboratory Medicine, UNC for the assistance in sciatic nerve histology. We thank members of the Krabbe Translational Research Network for their valuable intellectual inputs. Finally, we thank Dr. Tal Kafri for providing the codon-optimized mGALC and Dr. Mark Sands for providing founders for our twitcher mouse as well as the eGFP-positive transgenic mouse colony.

\section{REFERENCES CITED}

Baskin G, Alroy J, Li Y-T, Dayal Y, Raghavan SS, Sharer L. Galactosylceramide-lipidosis in Rhesus monkeys. Lab Invest. 1989; 60(7A)

Bessis N, GarciaCozar FJ, Boissier MC. Immune responses to gene therapy vectors: influence on vector function and effector mechanisms. Gene Ther. 2004; 11(Suppl 1):S10-17. [PubMed: 15454952]

Bucher T, Colle MA, Wakeling E, Dubreil L, Fyfe J, Briot-Nivard D, Maquigneau M, Raoul S, Cherel Y, Astord S, Duque S, Marais T, Voit T, Moullier P, Barkats M, Joussemet B. scAAV9 Intracisternal Delivery Results in Efficient Gene Transfer to the Central Nervous System of a Feline Model of Motor Neuron Disease. Hum Gene Ther. 2013; 24(7):670-682. [PubMed: 23799774]

Duchen LW, Eicher EM, Jacobs JM, Scaravilli F, Teixeira F. Hereditary leucodystrophy in the mouse: the new mutant twitcher. Brain. 1980; 103:695-710. [PubMed: 7417782]

Duffner PK, Caggana M, Orsini JJ, Wenger DA, Patterson MC, Crosley CJ, Kurtzberg J, Arnold GL, Escolar ML, Adams DJ, Andriola MR, Aron AM, Ciafaloni E, Djukic A, Erbe RW, Galvin-Parton P, Helton LE, Kolodny EH, Kosofsky BE, Kronn DF, Kwon JM, Levy PA, Miller-Horn J, Naidich TP, Pellegrino JE, Provenzale JM, Rothman SJ, Wasserstein MP. Newborn Screening for Krabbe Disease: the New York State Model. Pediatr Neurol. 2009; 40(4):245-252. [PubMed: 19302934]

Duque S, Joussemet B, Riviere C, Marais T, Dubreil L, Douar AM, Fyfe J, Moullier P, Colle MA, Barkats M. Intravenous Administration of Self-complementary AAV9 Enables Transgene Delivery to Adult Motor Neurons. Mol Ther. 2009; 17(7):1187-96. [PubMed: 19367261]

Escolar ML, Poe MD, Provenzale JM, Richards KC, Allison J, Wood S, Wenger DA, Pietryga D, Wall D, Champagne M, Morse R, Krivit W, Kurtzberg J. Transplantation of umbilical-cord blood in babies with infantile Krabbe's disease. N Eng J Med. 2005; 352(20):2069-2081.

Fankhauser R, Luginbuhl H, Hartley WJ. Leukodystrophie vom typus Krabbe beim hund. Schweiz Arch Tierheilkd. 1963; 105:10.

Federici T, Taub JS, Baum GR, Gray SJ, Grieger JC, Matthews KA, Handy CR, Passini MA, Samulski RJ, Boulis NM. Robust spinal motor neuron transduction following intrathecal delivery of AAV9 in pigs. Gene Ther. 2012; 19(8):852-859. [PubMed: 21918551]

Fletcher JL, Williamson P, Horan D, Taylor RM. Clinical signs and neuropathologic abnormalities in working Australian Kelpies with globoid cell leukodystrophy (Krabbe disease). J Am Vet Med Assoc. 2010; 237(6):682-688. [PubMed: 20839990]

Fletcher TF, Kurtz HJ, Low DG. Globoid cell leukodystrophy (Krabbe type) in the dog. J Am Vet Med Assoc. 1966; 149(2):165-172. [PubMed: 5950438]

Foust KD, Nurre E, Montgomery CL, Hernandez A, Chan CM, Kaspar BK. Intravascular AAV9 preferentially targets neonatal neurons and adult astrocytes. Nat Biotechnol. 2009; 27(1):59-65. [PubMed: 19098898]

Goncalves MA. Adeno-associated virus: from defective virus to effective vector. Virol J. 2005; 2:43. [PubMed: 15877812]

Gray SJ, Choi VW, Asokan A, Haberman RA, McCown TJ, Samulski RJ. Production of recombinant adeno-associated viral vectors and use in in vitro and in vivo administration. Curr Protoc Neurosci. 2011a; Chapter 4(Unit 4):17. [PubMed: 21971848]

Gray SJ, Matagne V, Bachaboina L, Yadav S, Ojeda SR, Samulski RJ. Preclinical differences of intravascular AAV9 delivery to neurons and glia: a comparative study of adult mice and nonhuman primates. Mol Ther. 2011b; 19(6):1058-1069. [PubMed: 21487395]

Gray SJ, Nagabhushan Kalburgi S, McCown TJ, Jude Samulski R. Global CNS gene delivery and evasion of anti-AAV-neutralizing antibodies by intrathecal AAV administration in non-human primates. Gene Ther. 2013; 20(4):450-459. [PubMed: 23303281] 
Grieger JC, Soltys S, Samulski RJ. Production of Recombinant Adeno-associated Virus Vectors Using Suspension HEK293 Cells and Continuous Harvest of Vector From the Culture Media for GMP FIX and FLT1 Clinical Vector. Mol Ther. 2016; 24(2):287-297. [PubMed: 26437810]

Haberman RP, Samulski RJ, McCown TJ. Attenuation of seizures and neuronal death by adenoassociated virus vector galanin expression and secretion. Nat Med. 2003; 9(8):1076-1080. [PubMed: 12858168]

Haurigot V, Marco S, Ribera A, Garcia M, Ruzo A, Villacampa P, Ayuso E, Anor S, Andaluz A, Pineda M, Garcia-Fructuoso G, Molas M, Maggioni L, Munoz S, Motas S, Ruberte J, Mingozzi F, Pumarola M, Bosch F. Whole body correction of mucopolysaccharidosis IIIA by intracerebrospinal fluid gene therapy. J Clin Invest. 2013; 123(8):3254-3271.

Hoogerbrugge PM, Poorthuis BJ, Romme AE, van de kamp JJ, Wagemaker G, van bekkum DW. Effect of bone marrow transplantation on enzyme levels and clinical course in the neurologically affected twitcher mouse. J Clin Invest. 1988; 81(6):1790-1794. [PubMed: 3290253]

Hu C, Busuttil RW, Lipshutz GS. RH10 provides superior transgene expression in mice when compared with natural AAV serotypes for neonatal gene therapy. J Gene Med. 2010; 12(9):766778. [PubMed: 20821747]

Kobayashi T, Yamanaka T, Jacobs JM, Teixeira F, Suzuki K. The Twitcher mouse: an enzymatically authentic model of human globoid cell leukodystrophy (Krabbe disease). Brain Res. 1980; 202(2): 479-483. [PubMed: 7437911]

Krivit W, Shapiro EG, Peters C, Wagner JE, Cornu G, Kurtzberg J, Wenger DA, Kolodny EH, Vanier MT, Loes DJ, Dusenbery K, Lockman LA. Hematopoietic stem-cell transplantation in globoid-cell leukodystrophy. N Eng J Med. 1998; 338(16):1119-1126.

Levine SM, Brown D. IL-6 and TNFalpha expression $\mathrm{n}$ brains of twitcher, quaking and normal mice. J Neuroimmunol. 1997; 73(1-2):47-56. [PubMed: 9058758]

Lin D, Dosante A, Macauley S, Levy B, Vogler C, Sands MS. Central nervous system-directed AAV2/5-mediated gene therapy synergizes with bone marrow transplantation in the murine model of globoid-cell leukodystrophy. Mol Ther. 2007; 15(1):44-52. [PubMed: 17164774]

Lin D, Fantz CR, Levy B, Rafi MA, Vogler C, Wenger DA, Sands MS. AAV2/5 vector expressing galactocerebrosidase ameliorates CNS disease in the murine model of globoid-cell leukodystrophy more efficiently than AAV2. Mol Ther. 2005; 12(3):422-430. [PubMed: 15996520]

McCarty DM, Fu H, Monahan PE, Toulson CE, Naik P, Samulski RJ. Adeno-associated virus terminal repeat (TR) mutant generates self-complementary vectors to overcome the rate-limiting step to transduction in vivo. Gene Ther. 2003; 10(26):2112-2118. [PubMed: 14625565]

McCarty DM, Monahan PE, Samulski RJ. Self-complementary recombinant adeno-associated virus (scAAV) vectors promote efficient transduction independently of DNA synthesis. Gene Ther. 2001; 8(16):1248-1254. [PubMed: 11509958]

McCarty DM, Young SM Jr, Samulski RJ. Integration of adeno-associated virus (AAV) and recombinant AAV vectors. Annu Rev Genet. 2004; 38:819-845. [PubMed: 15568995]

Nagara H, Ogawa H, Sato Y, Kobayashi T, Suzuki K. The twitcher mouse: degeneration of oligodendrocytes in vitro. Brain Res. 1986; 391(1):79-84. [PubMed: 3513905]

Okabe M, Ikawa M, Kominami K, Nakanishi T, Nishimune Y. 'Green mice' as a source of ubiquitous green cells. FEBS Letters. 1997; 407(3):313-319. [PubMed: 9175875]

Passini MA, Bu J, Richards AM, Treleaven CM, Sullivan JA, O'Riordan CR, Scaria A, Kells AP, Samaranch L, San Sebastian W, Federici T, Fiandaca MS, Boulis NM, Bankiewicz KS, Shihabuddin LS, Cheng SH. Translational fidelity of intrathecal delivery of self-complementary AAV9-survival motor neuron 1 for spinal muscular atrophy. Hum Gene Ther. 2014; 25(7):619630. [PubMed: 24617515]

Rafi MA, Rao HZ, Luzi P, Curtis MT, Wenger DA. Extended normal life after AAVrh10-mediated gene therapy in the mouse model of Krabbe disease. Mol Ther. 2012; 20(11):2031-2042. [PubMed: 22850681]

Rafi MA, Rao HZ, Luzi P, Luddi A, Curtis MT, Wenger DA. Intravenous injection of AAVrh10-GALC after the neonatal period in twitcher mice results in significant expression in the central and peripheral nervous systems and improvement of clinical features. Mol Genet metab. 2014; 114(3): 459-466. [PubMed: 25533112] 
Rafi MA, Rao HZ, Luzi P, Wenger DA. Long-term Improvements in Lifespan and Pathology in CNS and PNS After BMT Plus One Intravenous Injection of AAVrh10-GALC in Twitcher Mice. Mol Ther. 2015; 23(11):1681-90. [PubMed: 26329589]

Rafi MA, Rao HZ, Passini MA, Curtis M, Vanier MT, Zaka M, Luzi P, Wolfe JH, Wenger DA. AAVmediated expression of galactocerebrosidase in brain results in attenuated symptoms and extended life span in murine models of globoid cell leukodystrophy. Mol Ther. 2005; 11(5):734-744. [PubMed: 15851012]

Reddy AS, Kim JH, Hawkins-Salsbury JA, Macauley SL, Tracy ET, Vogler CA, Han X, Song SK, Wozniak DF, Fowler SC, Klein RS, Sands MS. Bone marrow transplantation augments the effect of brain- and spinal cord-directed adeno-associated virus $2 / 5$ gene therapy by altering inflammation in the murine model of globoid-cell leukodystrophy. J Neurosci. 2011; 31(27):99459957. [PubMed: 21734286]

Samaranch L, Salegio EA, San Sebastian W, Kells AP, Bringas JR, Forsayeth J, Bankiewicz KS. Strong cortical and spinal cord transduction after AAV7 and AAV9 delivery into the cerebrospinal fluid of nonhuman primates. Hum Gene Ther. 2013; 24(5):526-532. [PubMed: 23517473]

Samaranch L, Salegio EA, San Sebastian W, Kells AP, Foust KD, Bringas JR, Lamarre C, Forsayeth J, Kaspar BK, Bankiewicz KS. Adeno-associated virus serotype 9 transduction in the central nervous system of nonhuman primates. Hum Gene Ther. 2012; 23(4):382-389. [PubMed: 22201473]

Suzuki K, Suzuki Y. Globoid cell leucodystrophy (Krabbe's disease): deficiency of galactocerebroside beta-galactosidase. Proc Natl Acad Sci. 1970; 66(2):302-309. [PubMed: 5271165]

Tanaka K, Webster HD. Effects of psychosine (galactosylsphingosine) on the survival and the fine structure of cultured Schwann cells. J Neuropathol Exp Neurol. 1993; 52(5):490-498. [PubMed: 8360702]

Taniike M, Mohri I, Eguchi N, Irikura D, Urade Y, Okada S, Suzuki K. An apoptotic depletion of oligodendrocytes in the twitcher, a murine model of globoid cell leukodystrophy. J Neuropathol Exp Neurol. 1999; 58(6):644-653. [PubMed: 10374755]

Tornøe J, Kusk P, Johansen TE, Jensen PR. Generation of a synthetic mammalian promoter library by modification of sequences spacing transcription factor binding sites. Gene. 2002; 297(1-2):21-32. [PubMed: 12384282]

Wenger DA, Rafi MA, Luzi P. Molecular genetics of Krabbe disease (globoid cell leukodystrophy): diagnostic and clinical implications. Hum Mut. 1997; 10(4):268-279. [PubMed: 9338580]

Yang B, Li S, Wang H, Guo Y, Gessler DJ, Cao C, Su Q, Kramer J, Zhong L, Ahmed SS, Zhang H, He R, Desrosiers RC, Brown R, Xu Z, Gao G. Global CNS transduction of adult mice by intravenously delivered rAAVrh.8 and rAAVrh.10 and nonhuman primates by rAAVrh.10. Mol Ther. 2014; 22(7):1299-1309. [PubMed: 24781136]

Zhang H, Yang B, Mu X, Ahmed SS, Su Q, He R, Wang H, Mueller C, Sena-Esteves M, Brown R, Xu Z, Gao G. Several rAAV vectors efficiently cross the blood-brain barrier and transduce neurons and astrocytes in the neonatal mouse central nervous system. Mol Ther. 2011; 19(8):1440-1448. [PubMed: 21610699] 


\section{Significance Statement}

Krabbe disease is a devastating neurodegenerative disease. Hematopoietic stem cell transfer using cord blood or donor bone marrow is the current standard-of-care, which provides some limited efficacy in non-symptomatic infants and twitcher mice. We report that intrathecal AAV-mediated gene therapy in 10-11 day old twitcher mice can extend survival and improve pathology. Further, we show that bone marrow transplant synergizes with this approach. We propose that this study models the application of a combined therapy in human infants with Krabbe disease, and that the results are an important preclinical step towards the eventual application of gene therapy to Krabbe infants. 
A

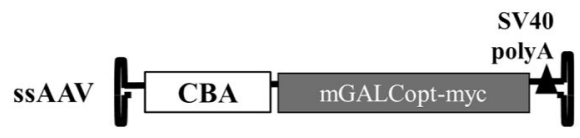

scAAV JeT

B

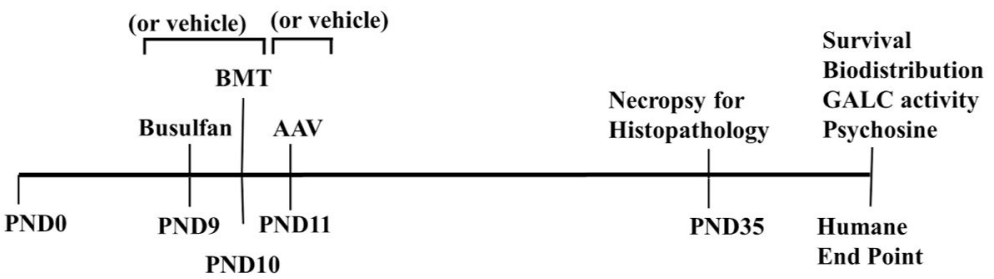

Figure 1. AAV construct designs and Outline of the study

(A) The expression cassette for the traditional single stranded-AAV included a codon optimized and myc tagged mouse GALC gene under a Chicken Beta Actin (CBA-CAGGS) promoter along with SV40 poly-adenylation signal. For the self-complementary AAV design, a reduced mGALCopt-myc gene starting with the $2^{\text {nd }}$ start codon is cloned under a minimal JeT promoter with a short synthetic polyA. (B) Time line for the interventions in the twitcher mice for the experiments outlined in the study. 


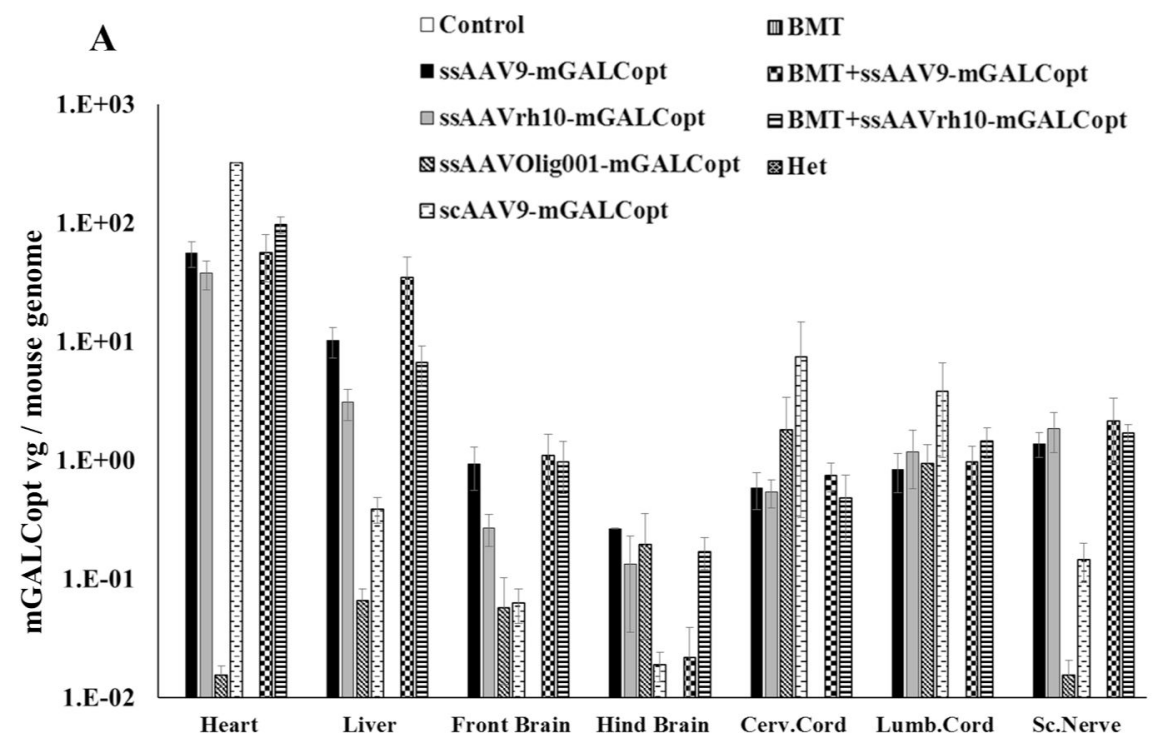

B

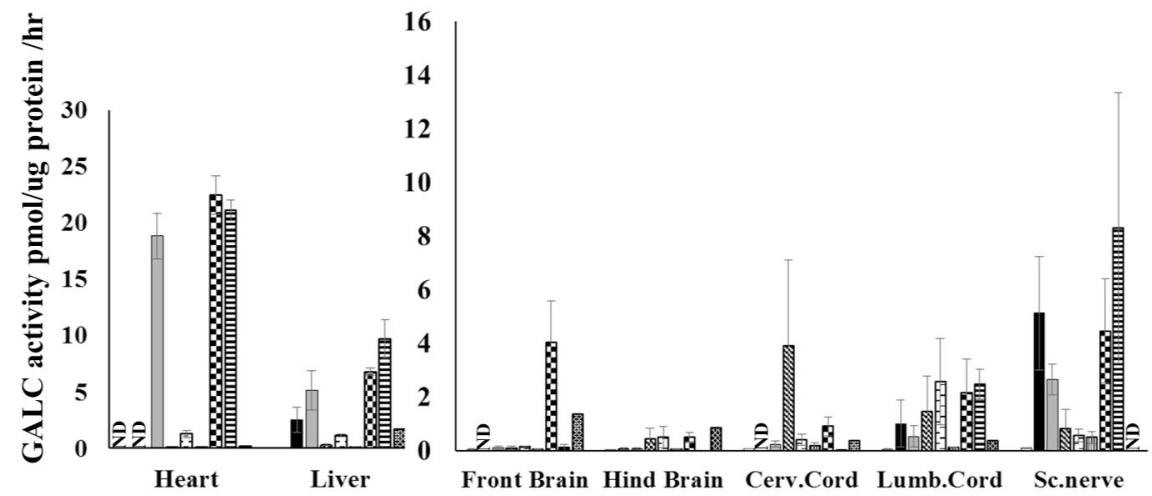

Figure 2. Biodistribution (A) and GALC Activity (B) in Twitcher tissues after Intrathecal delivery of AAV/mGALCopt with or without BMT

The twitcher mice were injected with vehicle or AAV/mGALCopt $\left(2 \times 10^{11} \mathrm{vg} / \mathrm{mouse}\right)$ via lumbar puncture on PND10-11. In combinations with BMT, the mice were treated with Busulfan (35mg/kg body weight) intra-peritoneally on PND8-9 followed by intra-peritoneal injection of bone marrow cells from syngeneic WT mice (40 million cells per mouse) one day later. The mice were euthanized at the humane end point and tissues were collected for various analyses. (A) The average number of mGALCopt vector genomes in major organs is plotted. The analyses included a minimum of five mice except for the combination treatment of BMT+ssAAVrh10-mGALCopt $(\mathrm{n}=2)$. No detectable viral genomes were found in control (vehicle) and BMT-only treated animals. (B) The mean GALC activity in major peripheral organs, CNS tissue and sciatic nerve for different treatments is plotted. For technical reasons, GALC activity was not analyzed for the heart, front brain and cervical cord from mice treated with ssAAV9/mGALCopt vector. GALC activity was measured in organs from at least 4 mice except for BMT+ssAAVrh10-mGALCopt $(n=2)$. 


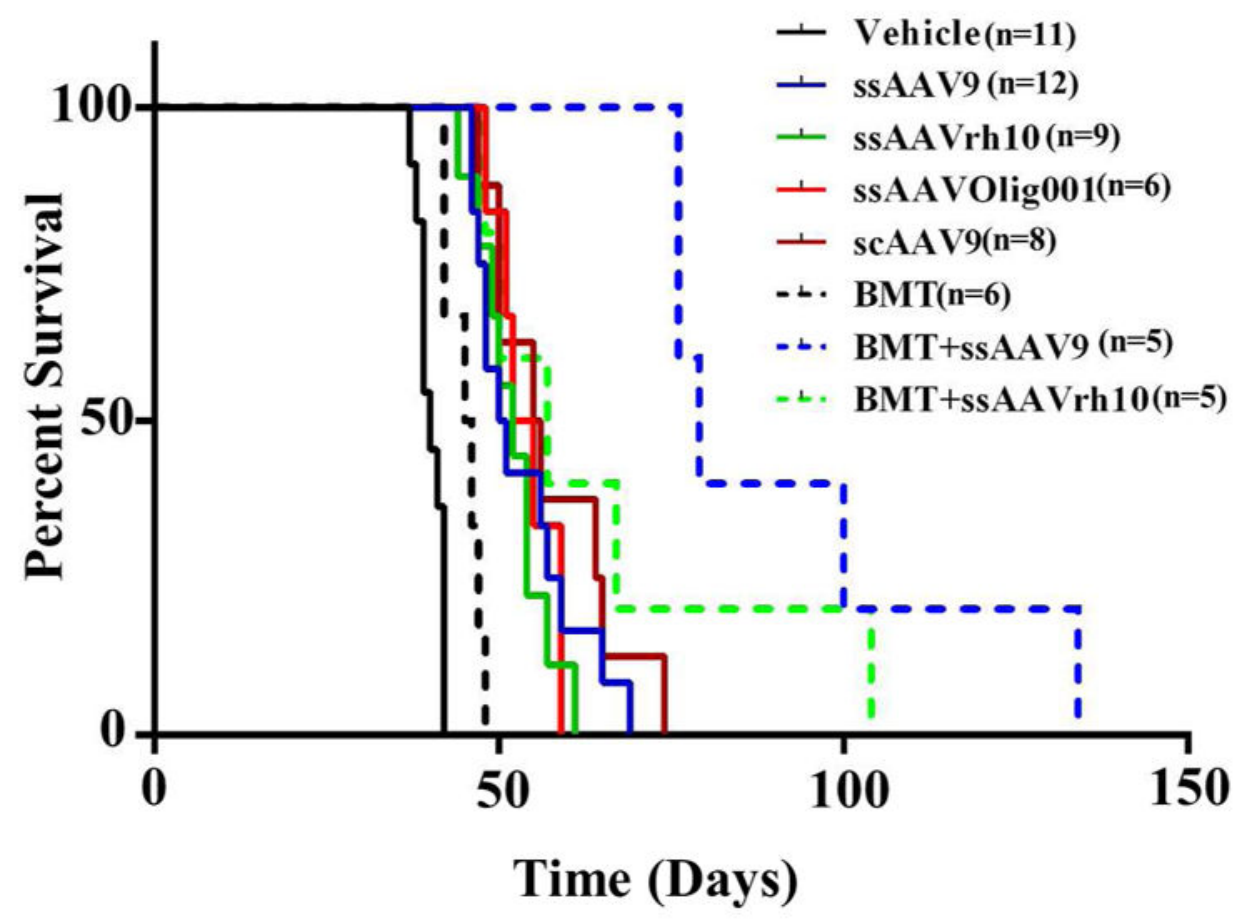

Figure 3. Extension of life span after intrathecal delivery of AAV/mGALCopt vectors alone and in combination with Bone Marrow Transplant

Twitcher mice were injected with vehicle or AAV/mGALCopt vectors at a uniform dose of $2 \times 10^{11} \mathrm{vg}$ per mouse on PND10-11 alone and in combination with BMT. The mice receiving BMT received an ip injection of Busulfan $(35 \mathrm{mg} / \mathrm{kg}$ body weight) on PND8-9, followed by an IP injection of 40 million bone marrow cells from syngeneic WT mice on PND9-10. They were monitored for weight loss on alternate days and a $20 \%$ loss of weight from the recorded peak weight was taken as the humane end point to record the survival. All treated mice had significant extension of life span compared to vehicle treated mice ( $\mathrm{p}<0.0001$ for ssAAV9, ssAAVrh10 and scAAV9; $\mathrm{p}=0.0003$ for ssOlig001; $\mathrm{p}=0.0021$ for BMT only; $\mathrm{p}=0.0008$ for BMT+ssAAV9 and $\mathrm{p}=0.0008$ for BMT + ssAAVrh10) when analyzed with Log rank (Mantel-Cox) test). BMT+ssAAV9/mGALCopt significantly ( $\mathrm{p}=0.0004$ ) enhanced survival when compared to ssAAV9 only. The comparison of ssAAVrh10 versus BMT+ssAAVrh10 and between the two BMT combinations were nonsignificant. 


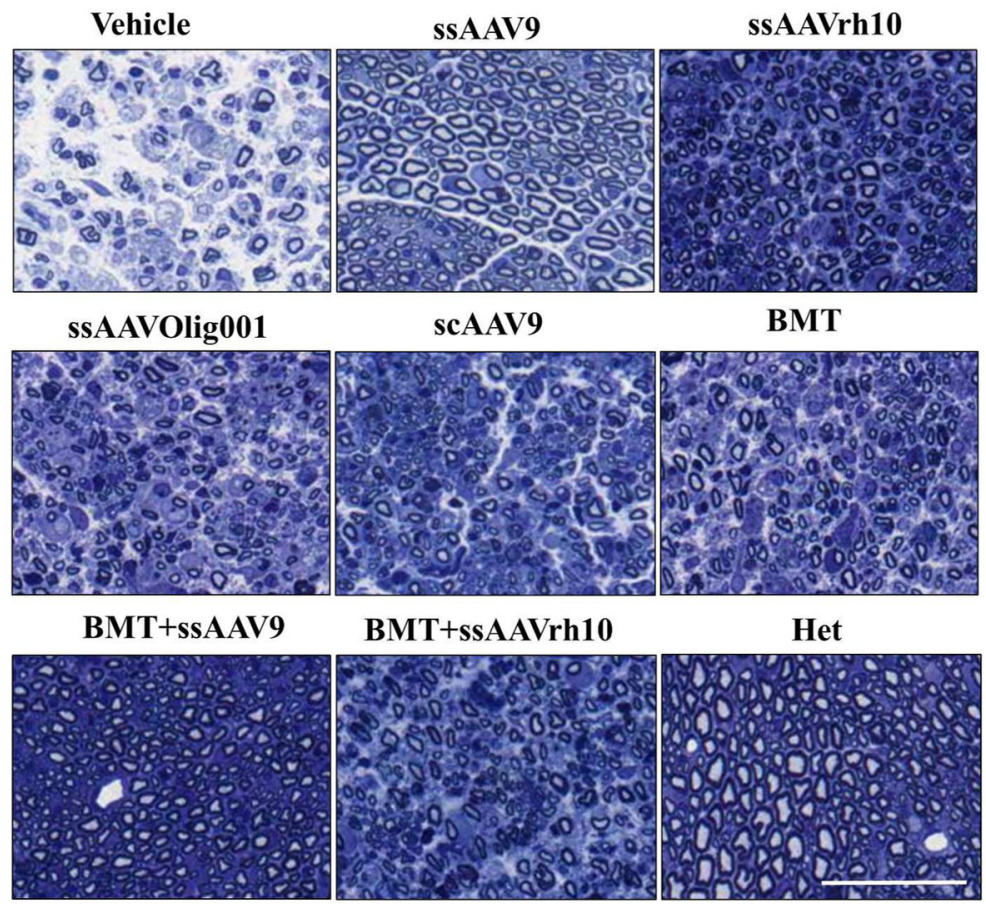

Figure 4. Sciatic Nerve histopathology after AAV/mGALCopt gene therapy with and without BMT in twitcher mice

Semi-thin $(1 \mu \mathrm{m})$ cross sections of sciatic nerve stained with toluidine blue from vehicletreated, AAV-only treated, BMT-only treated and BMT-AAV combination treated twitcher mice and normal heterozygous littermate are shown. All the images are representative of three mice except for BMT+ssAAVrh10 $(n=2)$. The scale bar is $200 \mu \mathrm{m}$. The quantitative analysis of mean G-ratios for different treatments is provided as Supplemental Figure 3. 

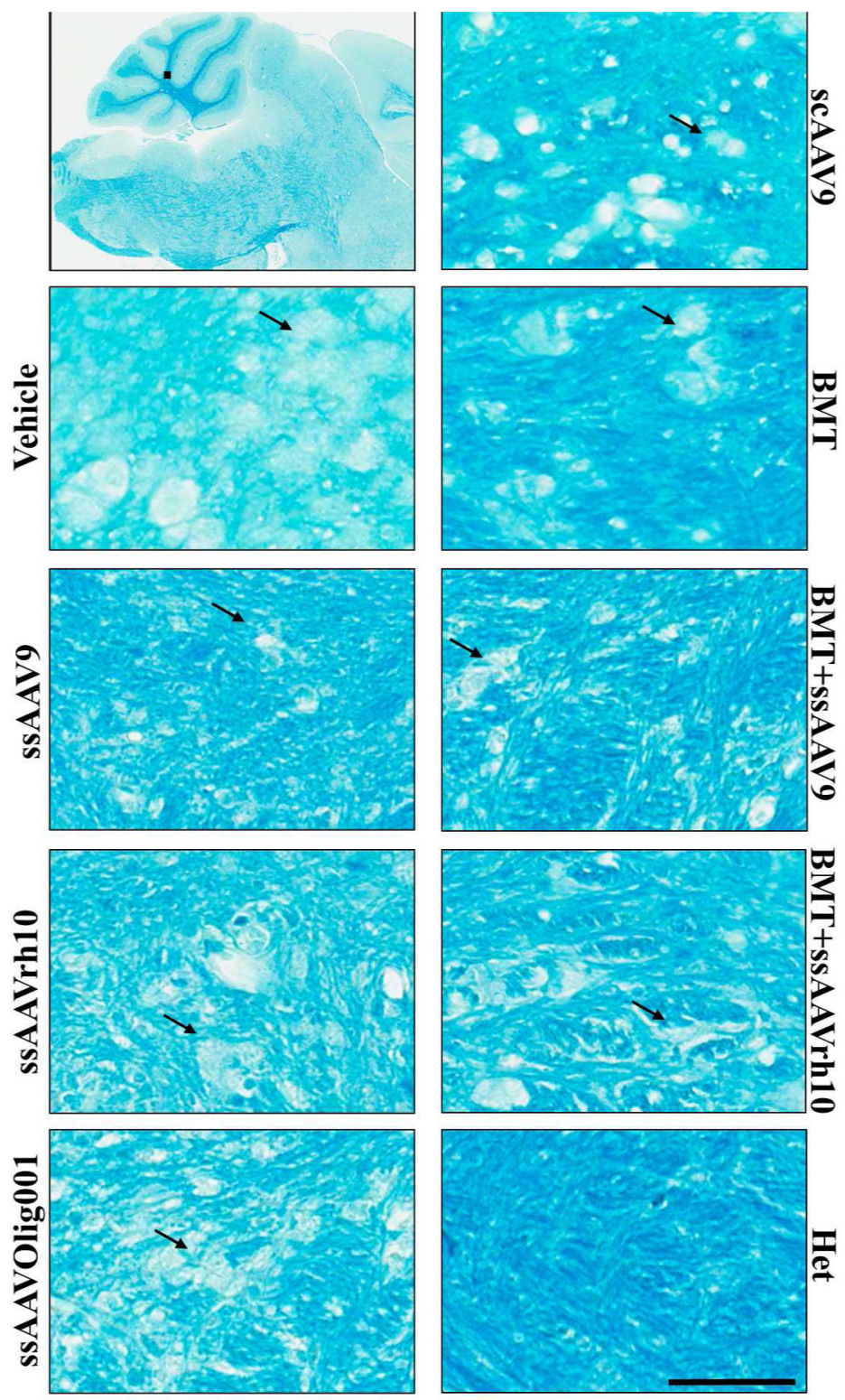

Figure 5. Histological Analysis of Focal Demyelination in the deep white matter of cerebellum after AAV/mGALCopt gene therapy with and without BMT in twitcher mice

Sagittal sections of the brain $(8-10 \mu \mathrm{m})$ were stained with Luxol Fast Blue to detect the level of myelination in twitcher mice treated with vehicle, AAV only, BMT only and BMT-AAV combinations. The higher magnification images are from the deep white matter of the cerebellar region. The arrows indicate areas with degenerated myelin. The scale bar is $200 \mu \mathrm{m}$. The upper left panel shows the location from which images were taken. The corresponding HE stained sections are provided in Supplemental Figure 4. Larger areas of selected treatments are provided as Supplemental Figures 7 - 9 . 

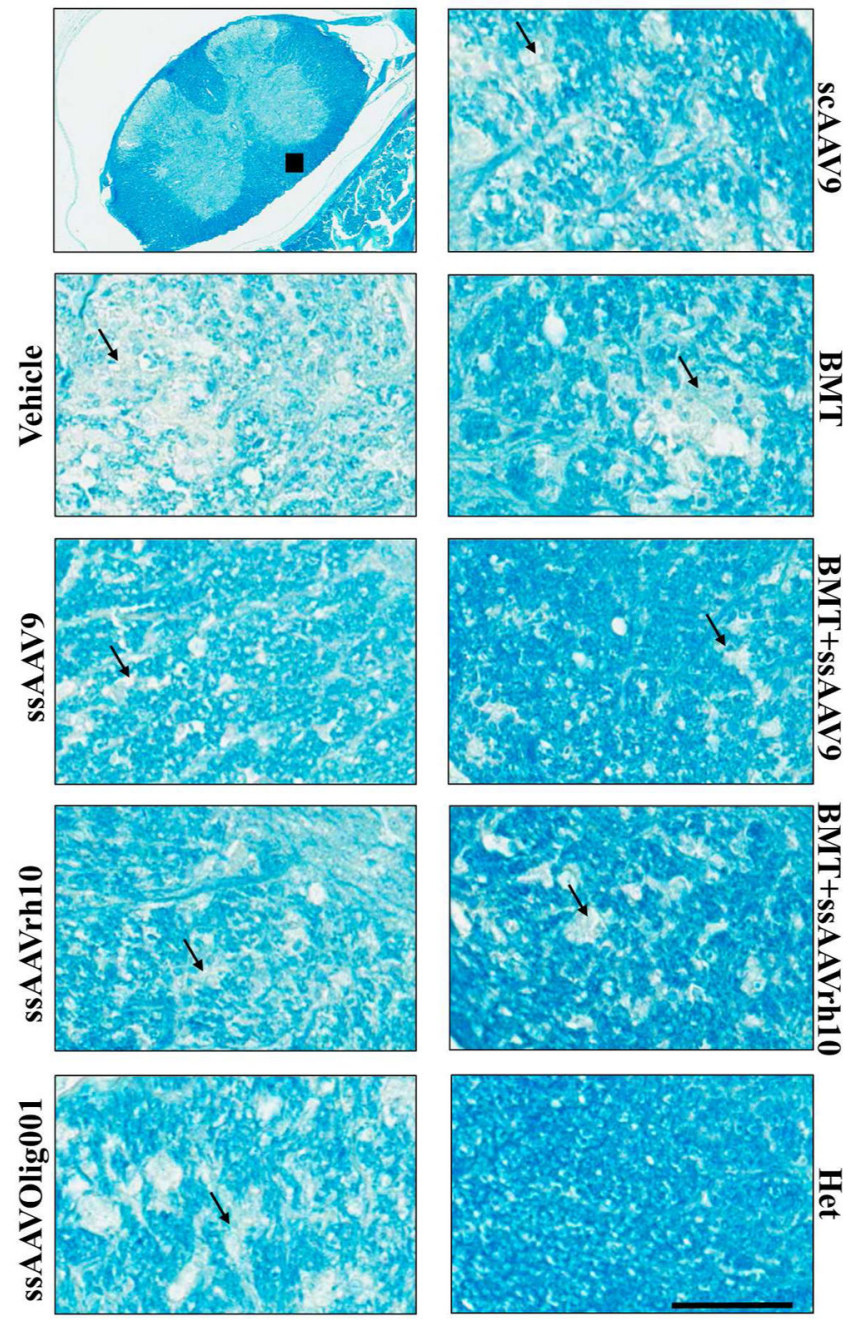

Figure 6. Histological Analysis of Focal Demyelination in the cervical spinal cord after AAV/ mGALCopt gene therapy with and without BMT in twitcher mice

Cross sections of the cervical spinal cord $(8-10 \mu \mathrm{m})$ were stained with Luxol Fast Blue to detect the level of myelination in twitcher mice treated with vehicle, AAV only, BMT only and BMT-AAV combinations. The images are from white matter tracts of ventral columns of the cord. The arrows indicate areas with degenerated myelin. The scale bar is $200 \mu \mathrm{m}$. The upper left panel shows the location from which images were taken. The corresponding $\mathrm{H}-\mathrm{E}$ stained sections are provided in Supplemental Figure 5. Larger area images of control and ssAAV9+BMT treatment are provided as Supplemental Figures 10 and 11. 

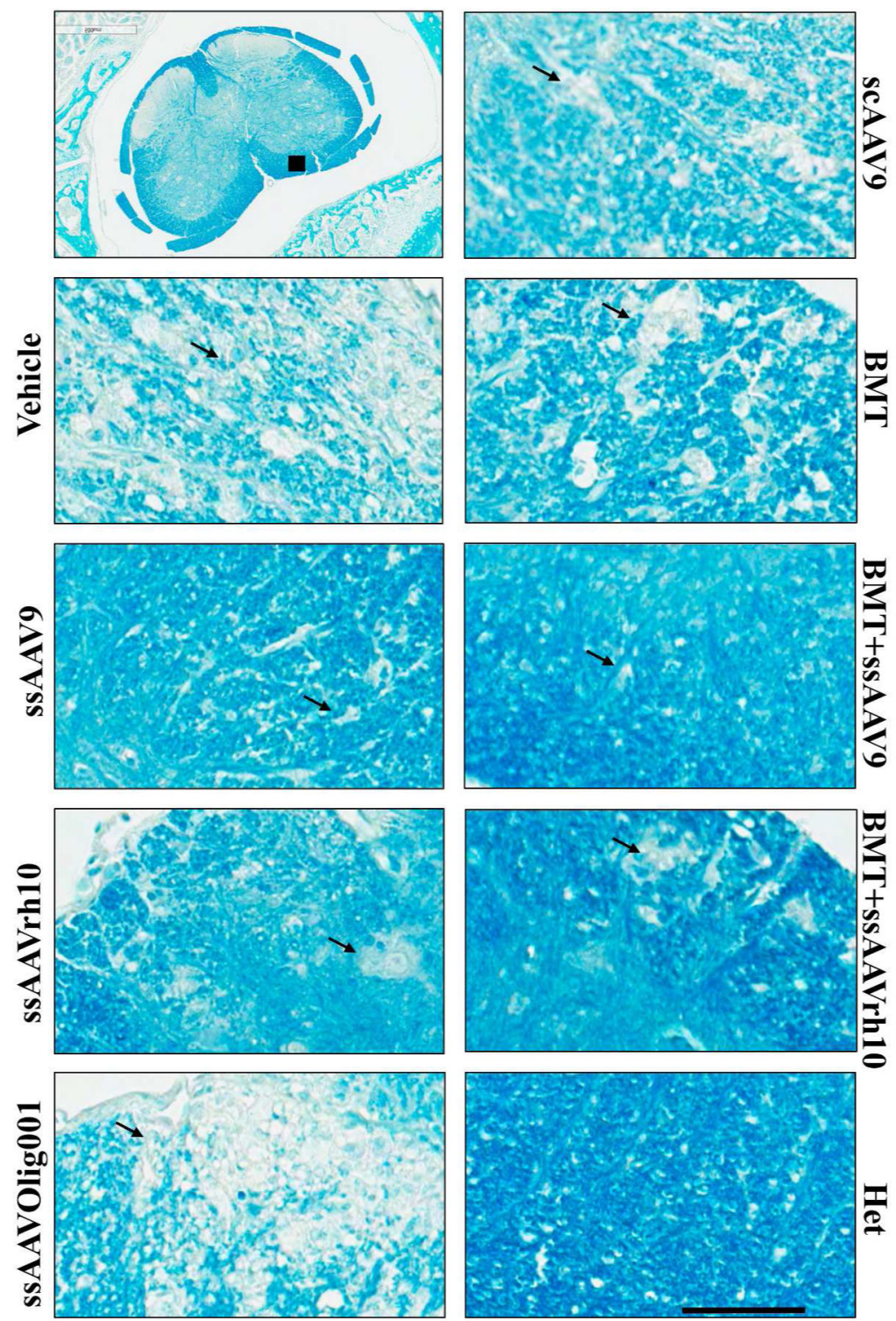

Figure 7. Histological Analysis of Focal Demyelination in the lumbar spinal cord after AAV/ mGALCopt gene therapy with and without BMT in twitcher mice

Cross sections of the lumbar spinal cord $(8-10 \mu \mathrm{m})$ were stained with Luxol Fast Blue to detect the level of myelination in twitcher mice treated with vehicle, AAV only, BMT only and BMT-AAV combinations. The images are from white matter tracts of ventral columns of the cord. The arrows indicate areas with degenerated myelin. The scale bar is $200 \mu \mathrm{m}$. The upper left panel shows the location from which images were taken. The corresponding H-E stained sections are provided in Supplemental Figure 6. Larger area images of control and ssAAV9+BMT treatment are provided as Supplemental Figures 12 and 13. 